\title{
Lithium Loaded Glass Fiber Neutron Detector Tests
}

\author{
JH Ely \\ LE Erikson \\ RT Kouzes \\ AT Lintereur \\ DC Stromswold
}

November 12, 2009

\section{Pacific Northwest}

NATIONAL LABORATORY

Proudly Operated by Battelle Since 1965 


\title{
DISCLAIMER
}

This report was prepared as an account of work sponsored by an agency of the United States Government. Neither the United States Government nor any agency thereof, nor Battelle Memorial Institute, nor any of their employees, makes any warranty, express or implied, or assumes any legal liability or responsibility for the accuracy, completeness, or usefulness of any information, apparatus, product, or process disclosed, or represents that its use would not infringe privately owned rights. Reference herein to any specific commercial product, process, or service by trade name, trademark, manufacturer, or otherwise does not necessarily constitute or imply its endorsement, recommendation, or favoring by the United States Government or any agency thereof, or Battelle Memorial Institute. The views and opinions of authors expressed herein do not necessarily state or reflect those of the United States Government or any agency thereof.

\author{
PACIFIC NORTHWEST NATIONAL LABORATORY \\ operated by \\ BATTELLE \\ for the \\ UNITED STATES DEPARTMENT OF ENERGY \\ under Contract DE-AC05-76RL01830
}

Printed in the United States of America

Available to DOE and DOE contractors from the

Office of Scientific and Technical Information,

P.O. Box 62, Oak Ridge, TN 37831-0062;

ph: (865) 576-8401

fax: (865) 576-5728

email: reports@adonis.osti.gov

Available to the public from the National Technical Information Service,

U.S. Department of Commerce, 5285 Port Royal Rd., Springfield, VA 22161

ph: (800) 553-6847

fax: (703) 605-6900

email: orders@ntis.fedworld.gov

online ordering: http://www.ntis.gov/ordering.htm 
PNNL-18988

\title{
Lithium Loaded Glass Fiber Neutron Detector Tests
}

\author{
JH Ely \\ LE Erikson \\ RT Kouzes \\ AT Lintereur \\ DC Stromswold
}

November 12, 2009

Pacific Northwest National Laboratory

Richland, Washington 99352 


\section{Executive Summary}

Radiation portal monitors used for interdiction of illicit materials at borders include highly sensitive neutron detection systems. The main reason for having neutron detection capability is to detect fission neutrons from plutonium. The currently deployed radiation portal monitors (RPMs) from Ludlum and Science Applications International Corporation (SAIC) use neutron detectors based upon ${ }^{3} \mathrm{He}$-filled gas proportional counters, which are the most common large neutron detector. There is a declining supply of ${ }^{3} \mathrm{He}$ in the world and, thus, methods to reduce the use of this gas in RPMs with minimal changes to the current system designs and sensitivity to cargo-borne neutrons are being investigated.

Four technologies have been identified as being currently commercially available, potential alternative neutron detectors to replace the use of ${ }^{3} \mathrm{He}$ in RPMs. These technologies are:

1) Boron trifluoride $\left(\mathrm{BF}_{3}\right)$-filled proportional counters,

2) Boron-lined proportional counters,

3) Lithium-loaded glass fibers, and

4) Coated non-scintillating plastic fibers.

Reported here are the results of tests of the lithium-loaded glass fibers option. This testing measured the neutron detection efficiency and gamma ray rejection capabilities of a small system manufactured by Nucsafe (Oak Ridge, TN). The Nucsafe neutron detector tested has several different software filters to discriminate against gamma radiation, the data was analyzed using each of the "liberal," "moderate," and "conservative" filters.

Results indicate that a Nucsafe neutron detector, with the current amounts of moderation and utilizing the moderate software filter, would need an active surface area of $0.47 \mathrm{~m}^{2}$ (compared to the area of 0.04125

$\mathrm{m}^{2}$ for the system tested) to have the same efficiency as a single ${ }^{3} \mathrm{He}$ tube in the current SAIC polyethylene moderator box. This active surface area might be reduced by the use of two or more layers of detectors. Dynamic tests with the Nucsafe neutron detector demonstrate that the system has a similar efficiency for a moving source as for a static source. The intrinsic gamma efficiency (rejection factor) was found to be on the order of $10^{-7}$ at the exposure rates tested (10 to $100 \mathrm{mR} / \mathrm{h}$ from a ${ }^{60} \mathrm{Co}$ source) with the moderate software filter, which meets the requirement for this parameter. The Gamma Absolute Rejection Ratio in the presence of neutrons (GARRn) was outside of the desired range with the moderate software filter for all of the exposure rates, indicating that there is miscounting of neutrons in the presence of large gamma exposure rates with this filter. Optimization of the design might allow a more conservative analysis with better gamma ray rejection while retaining the required neutron efficiency.

With the conservative software filter, the intrinsic gamma efficiency was improved to $10^{-8}$ but at the cost of significant reduced neutron detection efficiency (the conservative software filter resulted in a neutron efficiency seven times less than the moderate software filter). The GARRn value was within the desired range for all gamma ray exposure rates measured with the conservative filter.

The liberal filter results in a higher absolute neutron detection efficiency then either of the other filters. However, as with the moderate filter, the GARRn parameter is outside of the desired range for all of the gamma ray exposure rates measured.

Thus, the Nucsafe system tested could not simultaneously meet all three detection criteria with a single software filter. A larger system would need to be tested to verify that the efficiency scales linearly and to determine if the susceptibility to gamma radiation falls within the required range.

Page iv of vii 


\section{Acronyms and Abbreviations}

$\begin{array}{ll}\text { ANSI } & \begin{array}{l}\text { American National Standards Institute } \\ \text { atm }\end{array} \\ \text { CBP } & \text { Customs and Border Protection } \\ \text { cps } & \text { counts per second } \\ \text { DOE } & \text { U.S. Department of Energy } \\ \text { GARRn } & \text { Gamma Absolute Rejection Ratio in the presence of neutrons } \\ \text { PNNL } & \text { Pacific Northwest National Laboratory } \\ \text { PolyBox } & \text { polyethylene moderator/reflector box } \\ \text { PVT } & \text { Polyvinyl Toluene (plastic) scintillation gamma detector } \\ \text { RPM } & \text { Radiation Portal Monitor } \\ \text { RSP } & \text { Radiation Sensor Panel } \\ \text { SAIC } & \text { Science Applications International Corporation }\end{array}$




\section{Contents}

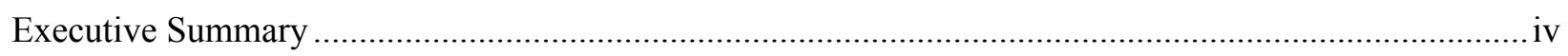

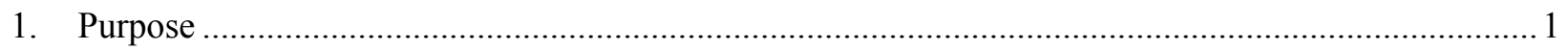

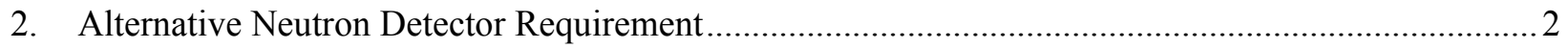

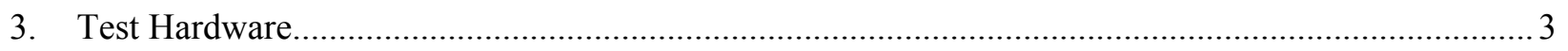

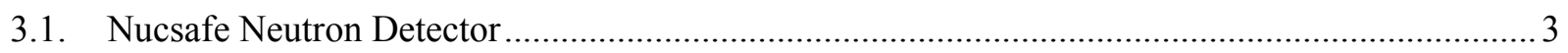

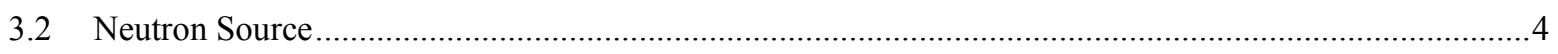

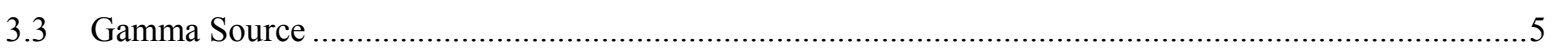

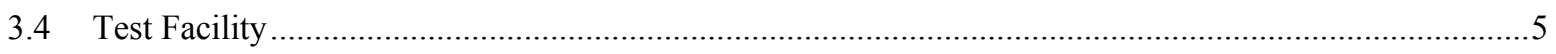

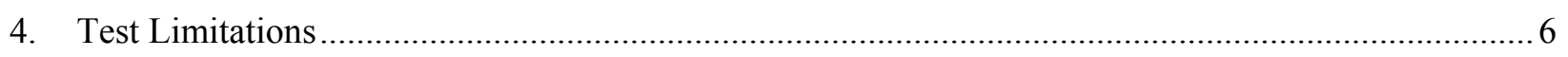

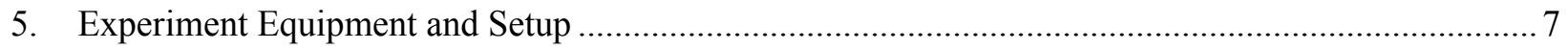

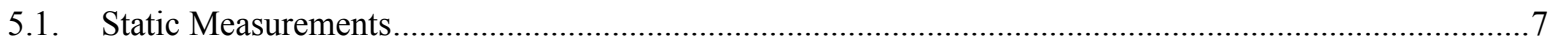

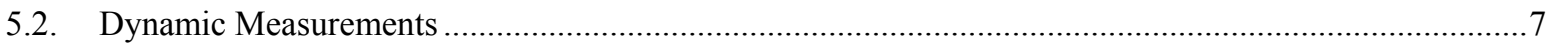

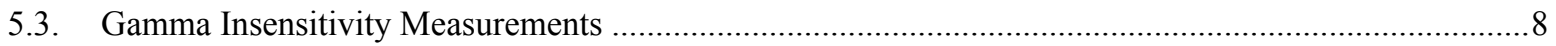

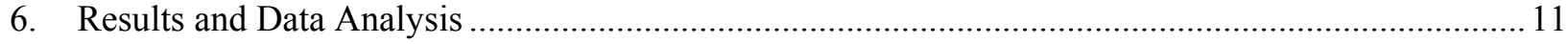

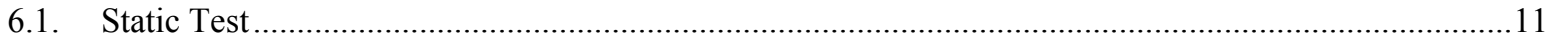

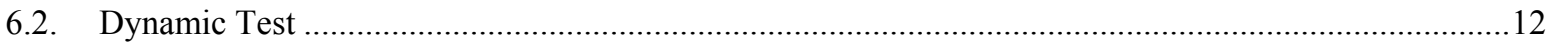

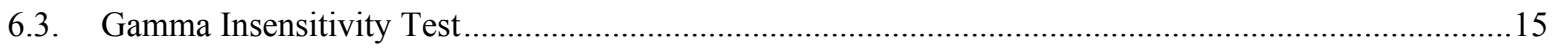

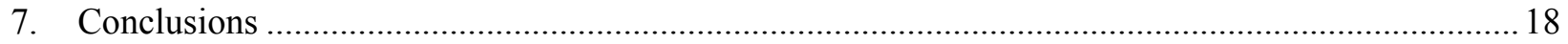

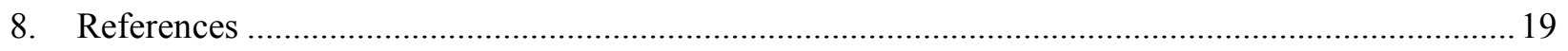




\section{Figures and Tables}

\section{Figures}

Figure 3.1: View of the Nucsafe detector being placed in the moderator box.......................................... 3

Figure 3.2: Nucsafe detector setup with tripod and bare ${ }^{252} \mathrm{Cf}$ source ................................................... 4

Figure 5.1: Shuttle track used to move the moderated and bare neutron source past the Nucsafe detector. 8

Figure 5.2: Nucsafe detector positioned for testing with the gamma ray and neutron sources................... 9

Figure 5.3: The detector positioned a few meters from the source for measurements in a high gamma

field

Figure 6.1: Count rate obtained with the three discrimination filters (black=liberal, red=moderate, green $=$ conservative) with the moderated and bare source for four different thicknesses of moderation.

Figure 6.2: Approximate system efficiency calculated for the Nucsafe system tested (black=liberal, red $=$ moderate, green $=$ conservative) .

Figure 6.4: Temporal profile for one complete cycle (down and back) of the shuttle at $2 \mathrm{mph}(0.9 \mathrm{~m} / \mathrm{s})$ with the moderated ${ }^{252} \mathrm{Cf}$ source.

Figure 6.5: Temporal profile for one complete cycle (down and back) of the shuttle at $5 \mathrm{mph}(2.2 \mathrm{~m} / \mathrm{s})$ with the moderated source.

Figure 6.6: Efficiency of the Nucsafe neutron detector in response to a neutron source and a gamma field (black=liberal, red $=$ moderate, green $=$ conservative)......

\section{Tables}

Table 5.1: Exposure rate versus distance for the gamma ray source .................................................... 9

Table 6.1: Count rate obtained for different time windows for the $2 \mathrm{mph}(0.9 \mathrm{~m} / \mathrm{s})$ dynamic test............ 14

Table 6.2: Count rate obtained for different time windows for the $5 \mathrm{mph}(2.2 \mathrm{~m} / \mathrm{s})$ dynamic test............ 14

Table 6.3: Neutron counts recorded with the liberal filter in the presence of a gamma field.................... 16

Table 6.4: Neutron counts recorded with the moderate filter in the presence of a gamma field. ............... 16

Table 6.5: Neutron counts recorded with the conservative filter in the presence of a gamma field........... 16

Table 6.6: Estimated number of photons incident on the active area of the detector calculated using the

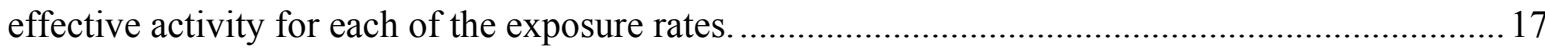

6.7: Estimates for the Absolute Efficiency and the Intrinsic Gamma Ray Efficiency and GARRn at a gamma exposure rate of $10 \mathrm{mR} / \mathrm{h}$. 


\section{Purpose}

Radiation portal monitor (RPM) systems used for interdiction of illicit materials at borders include highly sensitive neutron detection systems. The main reason for having neutron detection capability is to detect fission neutrons from plutonium. The currently deployed radiation portal monitors from Ludlum and Science Applications International Corporation (SAIC) use neutron detectors based upon ${ }^{3} \mathrm{He}$-filled gas proportional counters, which are the most common large neutron detector (Kouzes et al., 2008).

Within the last few years, the amount of ${ }^{3} \mathrm{He}$ available for use in gas proportional counter neutron detectors has become limited, while the demand has significantly increased, especially for homeland security applications (Kouzes 2009). In the near future, the limited supply is expected to curtail use of ${ }^{3} \mathrm{He}$; therefore, alternative neutron detection technologies are being investigated for use in the radiation portal monitor systems being deployed for border security applications (Van Ginhoven et al., 2009).

From a survey of technologies, only four technologies have been identified as currently commercially available, potential alternative neutron detectors to replace the use of ${ }^{3} \mathrm{He}$ in RPMs in the near-term. These technologies are:

1) Boron trifluoride $\left(\mathrm{BF}_{3}\right)$-filled proportional counters (from Reuter Stokes or LND),

2) Boron-lined proportional counters (from Reuter Stokes or LND),

3) Lithium-loaded glass fibers (from Nucsafe), and

4) Coated non-scintillating plastic fibers (from IAT).

Reported here are the results of tests of the lithium-loaded glass fibers option. This testing measured the neutron detection efficiency and gamma ray rejection capabilities of a system manufactured by Nucsafe (Oak Ridge, TN).

The purpose of this testing was to measure the efficiency and gamma sensitivity of the Nucsafe neutron detection system to determine if this technology can meet the specified neutron detection requirements. The measurements made as part of this testing included:

1) Response of the system with the original moderation configuration to moderated and unmoderated neutrons

2) Response of the system to moderated and un-moderated neutrons with varying amounts of detector moderation

3) Response of the system to a high gamma-ray exposure rate

4) Dynamic measurements with the original detector moderation made with the moderated and unmoderated neutron source. 


\section{Alternative Neutron Detector Requirement}

Lithium-loaded glass fibers are a possible neutron detector replacement technology for ${ }^{3} \mathrm{He}$-filled tubes. These fibers can be fashioned in dimensions that will fit in the space available in the currently deployed SAIC RPM polyethylene box that contains the ${ }^{3} \mathrm{He}$ tubes $[0.114 \mathrm{~m}$ deep $\times 0.304 \mathrm{~m}$ wide $\times 2.18 \mathrm{~m}$ tall (4.5 in. $\times 12$ in. $\times 85.7$ in.)], which provides a front surface area of $0.6627 \mathrm{~m}^{2}$. A system for replacement of the current neutron detectors in an SAIC RPM must fit within the space occupied by the present ${ }^{3} \mathrm{He}-$ based neutron detection system. The Nucsafe detector tested by Pacific Northwest National Laboratory (PNNL) had an active detector area of $0.04125 \mathrm{~m}^{2}$.

The SAIC systems were purchased under a specification (Stromswold et al., 2003) that requires a single radiation sensor panel (RSP) to meet the following requirements:

“A ${ }^{252} \mathrm{Cf}$ neutron source will be used for testing neutron sensor sensitivity:

- To reduce the gamma-ray flux, the source shall be surrounded by at least $0.5 \mathrm{~cm}$ of lead. To moderate the neutron spectrum, $2.5 \mathrm{~cm}$ of polyethylene shall be placed around the source.

- The absolute detection efficiency for such a ${ }^{252} \mathrm{Cf}$ source, located $2 \mathrm{~m}$ perpendicular to the geometric midpoint of the neutron sensor, shall be greater than $2.5 \mathrm{cps} / \mathrm{ng}$ of ${ }^{252} \mathrm{Cf}$. The neutron detector center shall be $1.5 \mathrm{~m}$ above grade for this test. (Note: 10 nanograms of ${ }^{252} \mathrm{Cf}$ is equivalent to 5.4 micro-Ci or $2.1 \times 10^{4} \mathrm{n} / \mathrm{s},{ }^{1}$ since ${ }^{252} \mathrm{Cf}$ has a $3.092 \%$ spontaneous fission $(\mathrm{SF})$ branch and 3.757 neutrons/SF.)

- The neutron detector shall not generate alarms due to the presence of strong gamma-ray sources. The ratio of neutron sensor gamma-ray detection efficiency to neutron detection shall be less than 0.001."

To evaluate the performance of alternate neutron detectors compared to what is currently deployed three criteria are considered: 1) neutron absolute detection efficiency, 2) intrinsic efficiency of gammas detected as neutrons, and 3) Gamma Absolute Rejection Ratio in the presence of neutrons (GARRn) (Kouzes et al., 2009).

The neutron absolute detection efficiency $\left(\epsilon_{\mathrm{abs} n}\right)$ required is that previously specified $(2.5 \mathrm{cps} / \mathrm{ng}$ from a ${ }^{252} \mathrm{Cf}$ source at $2 \mathrm{~m}$ in the specified pig). The intrinsic efficiency of gamma rays detected as neutrons $\left(\epsilon_{\mathrm{int}}\right.$ $\gamma_{\mathrm{n}}$ ) is defined as the number of events that are counted as neutrons in the presence of a gamma ray source divided by the number of photons hitting the detector area. The intrinsic efficiency of gamma rays detected as neutrons shall be less than or equal to $10^{-6}$ at an exposure rate of $10 \mathrm{mR} / \mathrm{h}$ for a detector with the capability to meet the neutron absolute detection efficiency. The GARRn is the number of events that are counted as neutrons $\left(\epsilon_{\mathrm{abs} \gamma \mathrm{n}}\right)$ in the presence of both gamma ray and neutron sources divided by $\epsilon_{\mathrm{abs} n}$; both measurements are made with the neutron source in the same position. The requirement for GARRn is $0.9 \leq \mathrm{GARRn} \leq 1.1$ at a $10 \mathrm{mR} / \mathrm{h}$ gamma ray exposure rate.

In addition, these systems are required to meet all aspects of the ANSI N42.35 standard (ANSI 2004). A summary of neutron detection systems in RPMs can be found in Kouzes et al (2007).

\footnotetext{
${ }^{1} 2.3 \times 10^{4} \mathrm{n} / \mathrm{s}$ is the current best known and used value
} 


\section{Test Hardware}

\subsection{Nucsafe Neutron Detector}

The Nucsafe detector tested consists of three core sensors that are $50 \mathrm{~mm}$ wide by $0.275 \mathrm{~m}$ long by 25.4 $\mathrm{mm}$ deep. There are 5 ribbons of glass fiber placed in the layers of each detector core utilizing approximately 2700 fibers/core. Each fiber detector is $150 \mu \mathrm{m}$ in diameter. The active area of the detector is $0.04125 \mathrm{~m}^{2}$ located in a $0.09 \mathrm{~m}^{2}$ aluminum box. The aluminum box is seen in Figure 3.1 being placed into a polyethylene moderator box.

The ${ }^{6} \mathrm{Li}$ in the glass fiber serves as the thermal neutron absorber. Thermal neutrons result in charged particles from the ${ }^{6} \mathrm{Li}(\mathrm{n}, \alpha)^{3} \mathrm{H}$ reaction and the charged particles produce light in the fibers, which conduct the light to photomultiplier tubes.

Nucsafe provided a polyethylene moderator box for the tests. The box has external dimensions of $0.26 \mathrm{~m}$ x $0.50 \mathrm{~m} \mathrm{x} 0.10 \mathrm{~m}$ (the front surface area is $0.13 \mathrm{~m}^{2}$ ), with the polyethylene being $19-\mathrm{mm}$ thick on the front and sides, and 38-mm thick on the back. Lead $(\sim 3.5 \mathrm{~mm})$ was included by the vendor on the front of the detector, inside the polyethylene box. The system in position for testing is seen in Figure 3.2.

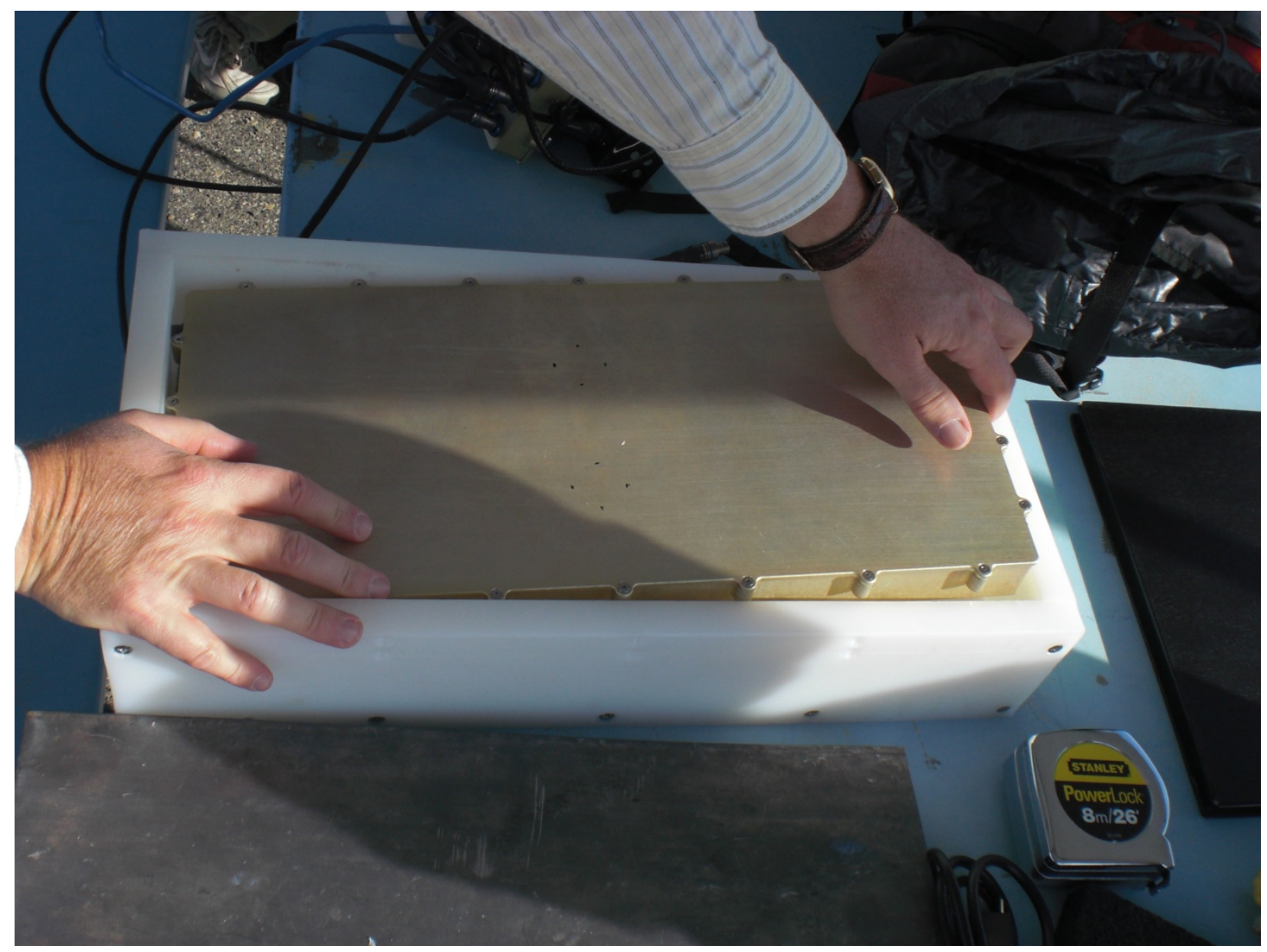

Figure 3.1: View of the Nucsafe detector being placed in the moderator box. 


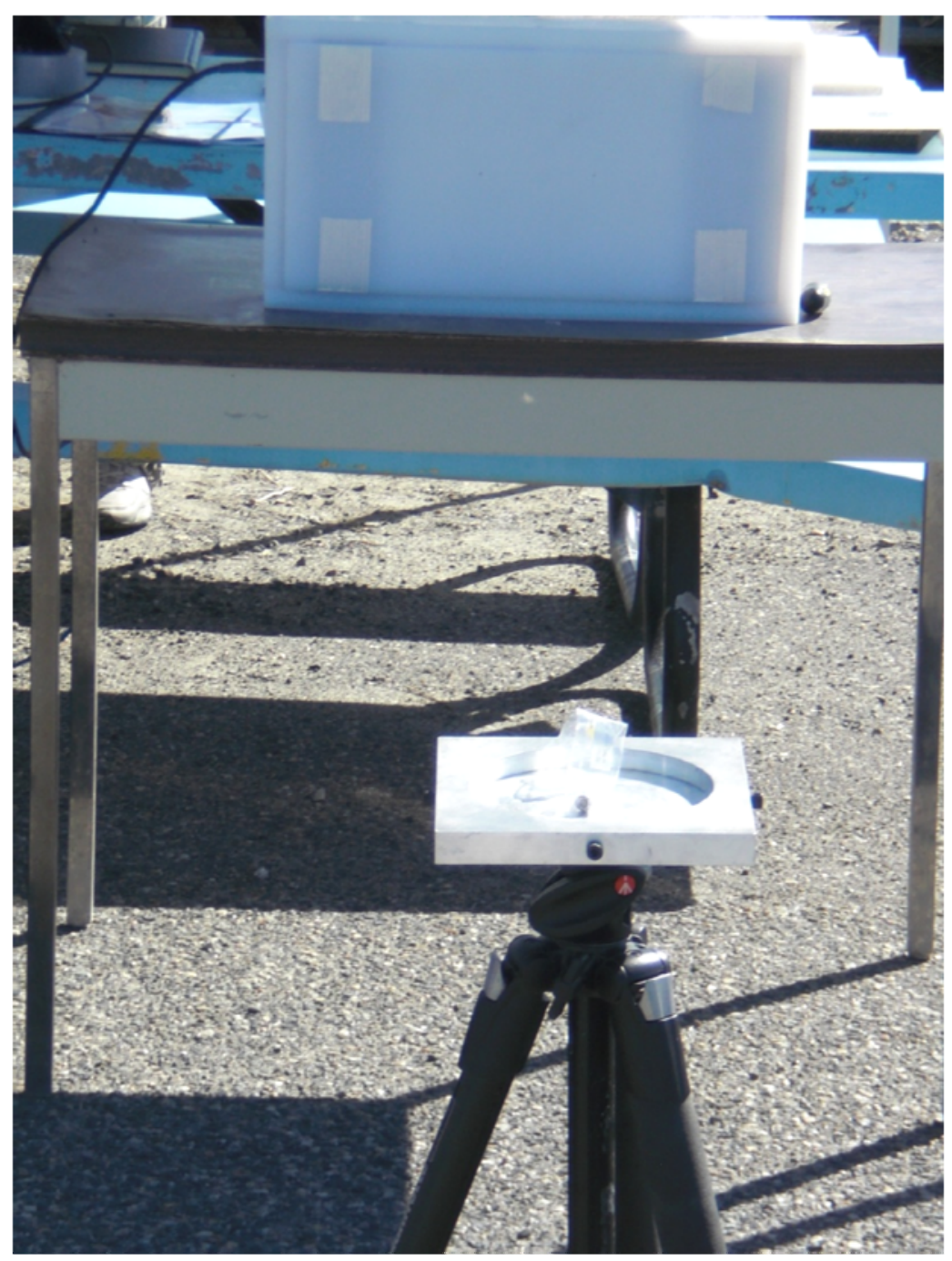

Figure 3.2: Nucsafe detector setup with tripod and bare ${ }^{252} \mathrm{Cf}$ source.

The electronics for the detector process the signals produced by the fibers to provide the neutron count rate. These signals are processed through software filters to yield discrimination between neutron and gamma ray pulses.

\subsection{Neutron Source}

The neutron source used for this test was ${ }^{252} \mathrm{Cf}$. The source was purchased from Isotope Products Laboratory (IPL) and given a PNNL ID of 60208-16. The source was measured by IPL to be $20 \pm 3 \mu \mathrm{Ci}$ on February 15, 2009. The source composition was $93.832 \%{ }^{252} \mathrm{Cf}, 0.0309 \%{ }^{251} \mathrm{Cf}, 6.016 \%{ }^{250} \mathrm{Cf}$, and $0.117 \%{ }^{249} \mathrm{Cf}$ according to IPL. Using these values, the source used was estimated to be $17.68 \mu \mathrm{Ci}$ for this testing. This activity corresponds to an estimated emanation rate of $6.88 \times 10^{4} \mathrm{n} / \mathrm{s}$ using the conversion factor for ${ }^{252} \mathrm{Cf}$ stated in Section 2.

The $17.68 \mu \mathrm{Ci}$ source was used in two configurations: 1) moderated ( $25 \mathrm{~mm}$ of polyethylene moderator outside of $5 \mathrm{~mm}$ of lead) and 2) bare (encased only in the stainless steel capsule from the source vendor). 
For the static tests the source was placed on a tripod. For the dynamic tests, the source was placed on a shuttle that moved the source along a track past the detector at a constant speed.

\subsection{Gamma Source}

$\mathrm{A}{ }^{60} \mathrm{Co}$ source was used for the gamma sensitivity tests. The exposure rate at the detector from the source was provided by the staff at Building 318. Due to the uncertainty in the original source strength and the large scatter contribution caused by the source being located indoors the source activity on the day of the tests was determined by calculating the source strength necessary to deliver the measured dose rate at each position. This method resulted in a source strength of approximately $118 \mathrm{mCi}$ being calculated for the day of the testing.

\subsection{Test Facility}

The tests were performed at the $331 \mathrm{G}$ Integration Test Facility and in the 318 Building, both located at PNNL in Richland, WA. On Tuesday, September 8, 2009, the static and dynamic tests were performed. The gamma insensitivity measurements with the ${ }^{60}$ Co source were performed on Tuesday, September 15 , 2009. 


\section{Test Limitations}

There were several limitations for this test and results may change with different conditions.

- Only one location was used for each set of measurements, with the corresponding background. Since the testing was focused on net results (background subtracted) this should have little effect on the overall results.

- Only one Nucsafe detector system was tested. Results may change with different detector geometries.

- Uncertainty in the source strength was the main limitation to the test results. 


\section{Experiment Equipment and Setup}

\subsection{Static Measurements}

Static measurements were made first with the original moderator thickness and then with a series of varied moderation thicknesses. The neutron source was located on a tripod $2 \mathrm{~m}$ from the front panel of the detector housing and at a height that positioned the source in the center of the detector $(1.3 \mathrm{~m}$ above the ground).

Data were acquired over $\sim 5$ minute time intervals (with a stopwatch) with two neutron source configurations. For one configuration the source was located in a polyethylene pig ( $6 \mathrm{~mm}$ of lead and 25 $\mathrm{mm}$ of polyethylene) and for the other configuration the source was used bare. The original Nucsafe detector moderator arrangement was $19 \mathrm{~mm}(0.75 \mathrm{in}$.) of polyethylene on the front and sides and $38 \mathrm{~mm}$ (1.5 in.) of polyethylene on the back of the detector. For the altered moderator thickness measurements, the following amounts of polyethylene were used on the front of the detector (the moderation on the back and sides of the detector was left the same):

1. $0 \mathrm{~mm}$

2. $19 \mathrm{~mm}$ (original moderation)

3. $38 \mathrm{~mm}$

4. $47.6 \mathrm{~mm}$

The static measurements were used to obtain data that allowed the Nucsafe detector efficiency to be compared to the efficiency of the ${ }^{3} \mathrm{He}$ tubes used in the current systems.

\subsection{Dynamic Measurements}

Dynamic measurements were performed to ensure that the temporal profiles from the Nucsafe detector are similar to the temporal profiles from the ${ }^{3} \mathrm{He}$-based neutron detector. Any significant change in the temporal profile may indicate that changes in the alarm algorithm might be required if fibers are chosen to replace ${ }^{3} \mathrm{He}$. The dynamic measurements were also performed to verify that the count rate recorded with the source in motion was comparable to the static count rate.

To make the dynamic measurements the neutron source, in the moderated configuration, was placed on an automated shuttle that ran along a track (Figure 5.1). The center of the track was $1 \mathrm{~m}$ from the front of the detector housing and $1.3 \mathrm{~m}$ (51 in.) above the ground, which placed the center of the source at the same height as the center of the active detector area. The track moved the source past the detector at the two speeds that correspond to primary and secondary screening, $2.2 \mathrm{~m} / \mathrm{s}(5 \mathrm{mph})$ and $0.9 \mathrm{~m} / \mathrm{s}(2 \mathrm{mph})$, respectively. 


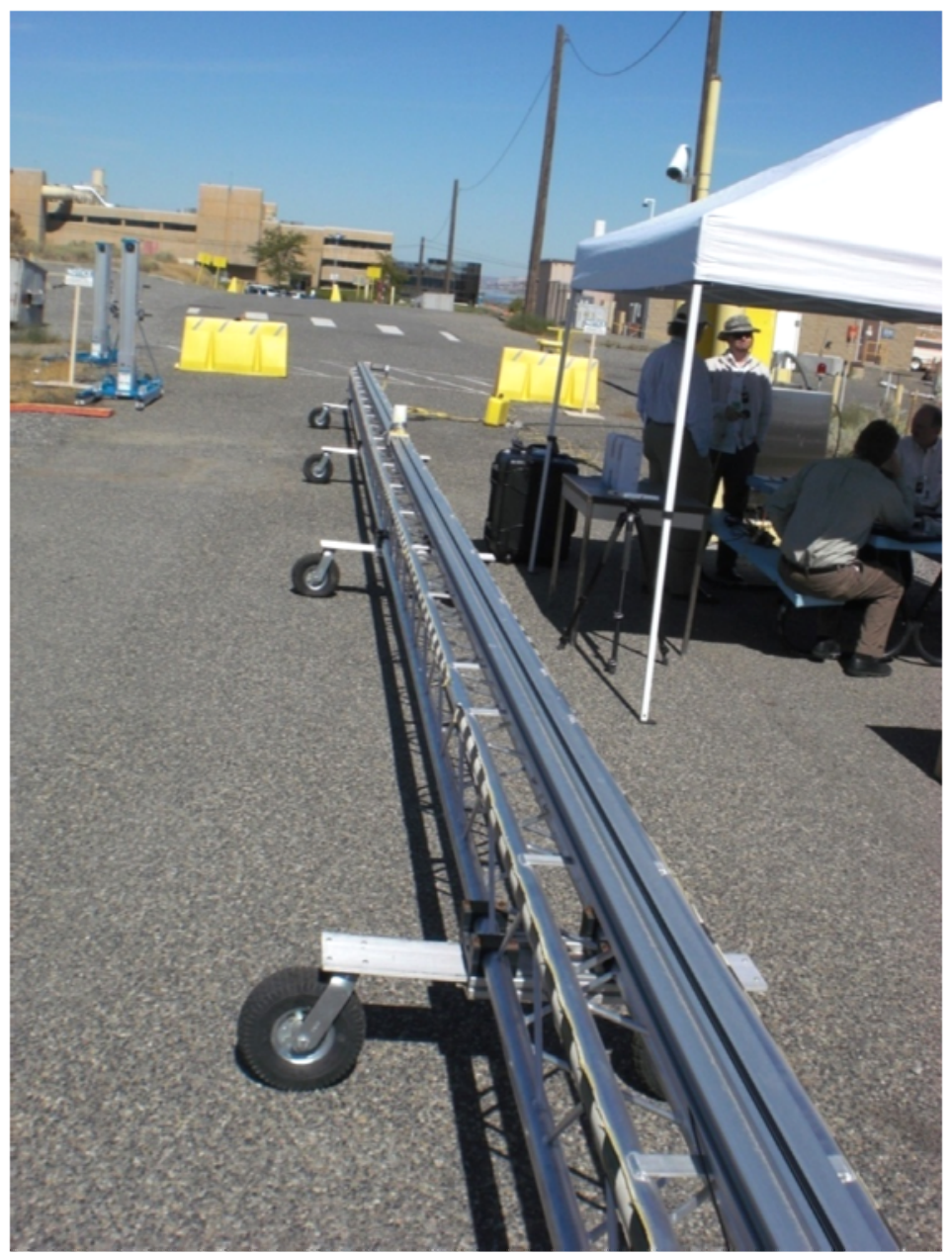

Figure 5.1: Shuttle track used to move the moderated and bare neutron source past the Nucsafe detector.

\subsection{Gamma Insensitivity Measurements}

The detector sensitivity to gamma rays was tested with a large ${ }^{60} \mathrm{Co}$ gamma source. Measurements were made in Building 318 with the gamma-ray source by itself and the gamma-ray source with a neutron source placed $2 \mathrm{~m}$ from the back of the detector. The ${ }^{60} \mathrm{Co}$ gamma source is stored in a vault for the 'closed' position and moved remotely on a pneumatic shuttle system into the center of the room for the 'open' position. Table 5.1 gives the exposure rate versus distance for the gamma ray exposures.

The detector (middle of Figure 5.2 with the neutron source in the foreground and the gamma ray source in the background) was moved to different distances from the ${ }^{60}$ Co source (Figure 5.3 foreground with the detector in the background) to obtain the desired exposure rates on the detector's front face when the source was shuttled into the end of the source tube. 


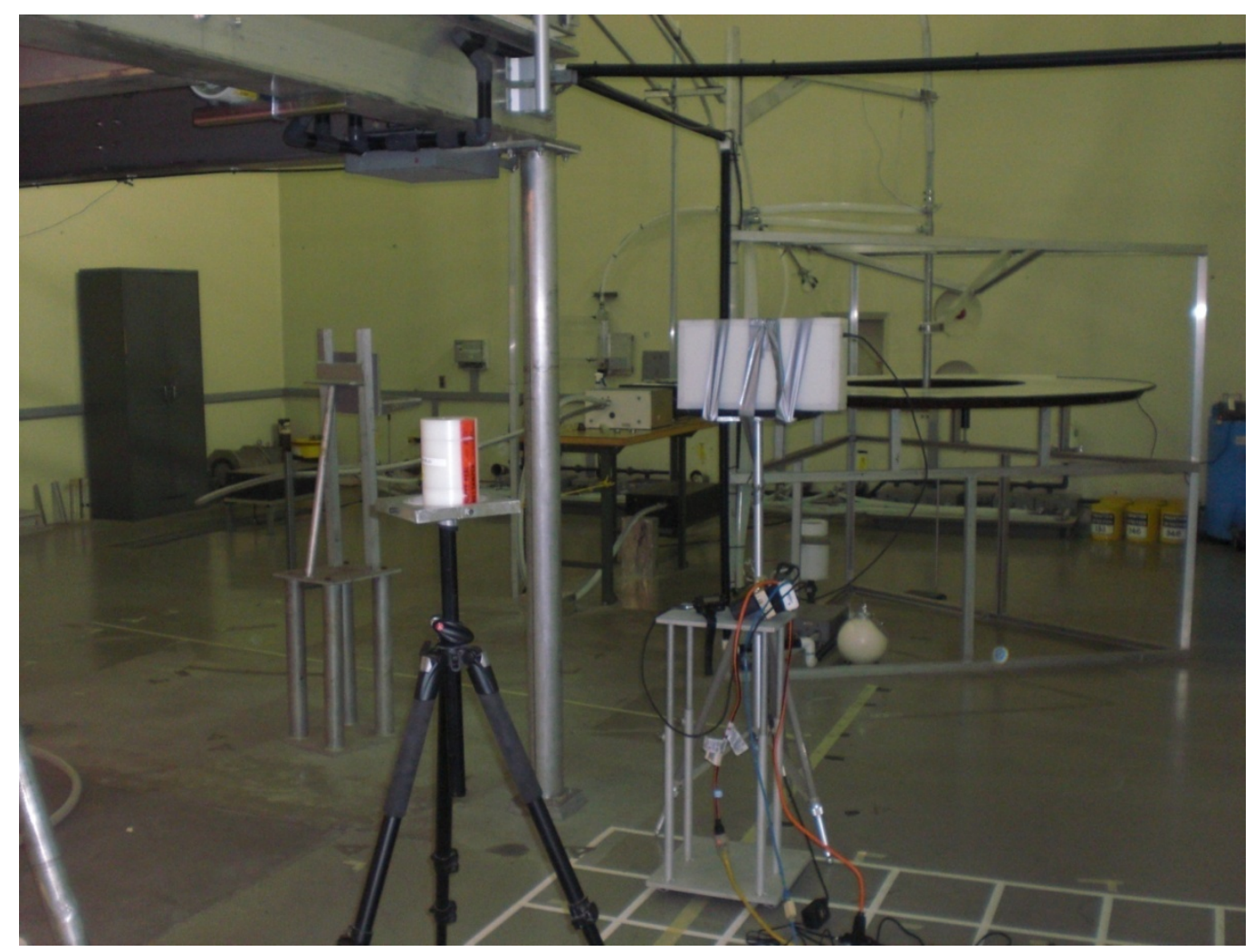

Figure 5.2: Nucsafe detector positioned for testing with the gamma ray and neutron sources.

Table 5.1: Exposure rate versus distance for the gamma ray source.

\begin{tabular}{|c|c|}
\hline Exposure Rate (mR/h) & Distance (m) \\
\hline 10 & 3.88 \\
\hline 20 & 2.74 \\
\hline 30 & 2.24 \\
\hline 40 & 1.94 \\
\hline 50 & 1.73 \\
\hline 70 & 1.47 \\
\hline 100 & 1.23 \\
\hline
\end{tabular}

Five-minute measurements were made for four configurations at each position:

1. Source closed (background)

2. Source open

3. Source open and the $17.68 \mu \mathrm{Ci}$ neutron source located on a tripod $2 \mathrm{~m}$ from the back of the detector

4. Source closed and the $17.68 \mu \mathrm{Ci}$ neutron source located on a tripod $2 \mathrm{~m}$ from the back of the detector. 


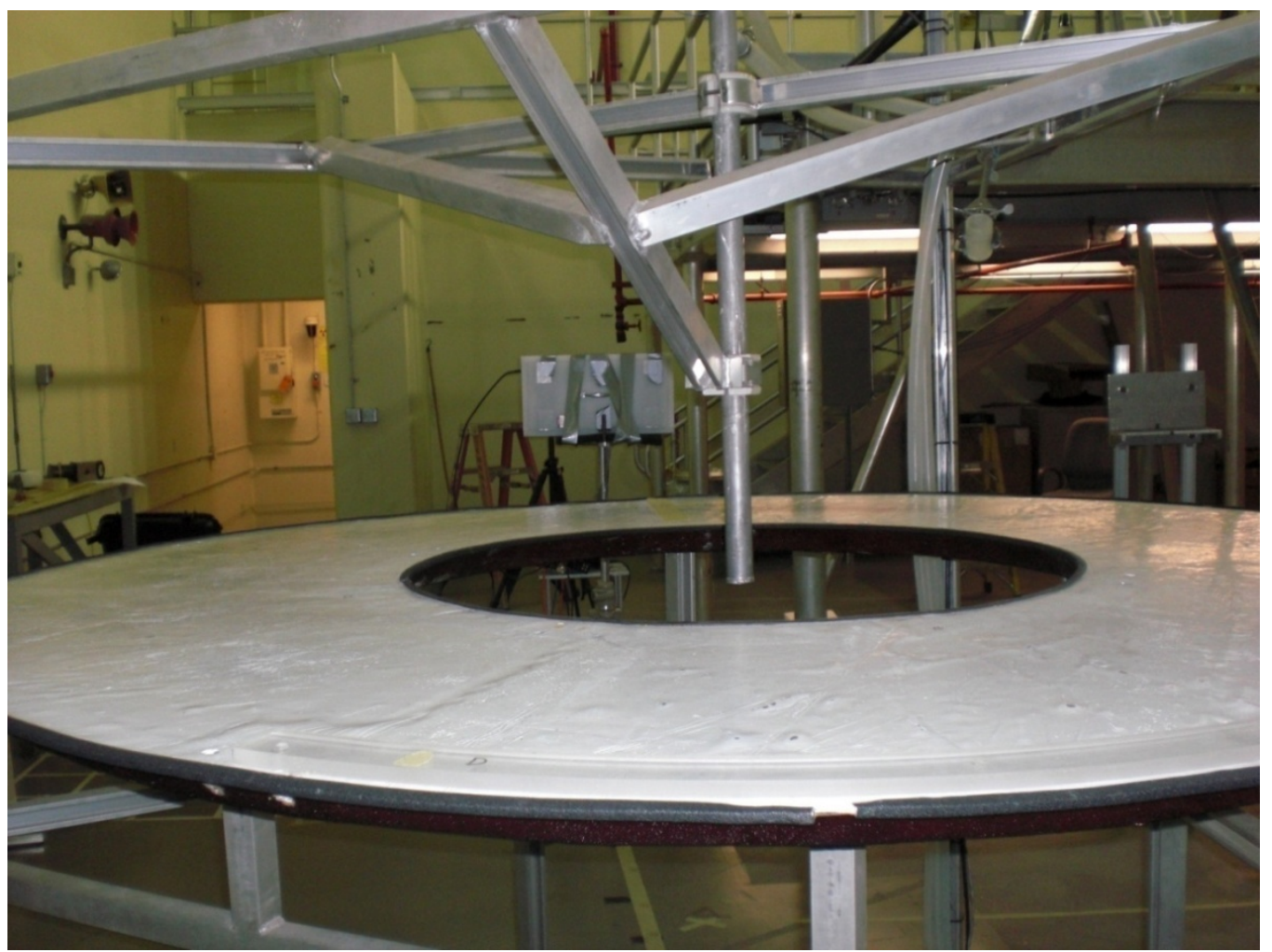

Figure 5.3: The detector positioned a few meters from the source for measurements in a high gamma field. 


\section{Results and Data Analysis}

\subsection{Static Test}

The data were collected using the Nucsafe system software. The default Nucsafe software settings were not altered for any of the tests. Nucsafe utilizes three data processing filters (liberal, moderate and conservative); the filter used by the software is selected automatically based on how strong a gamma ray field is present. The liberal software filter results in the fewest rejected counts, but this filter is only used in very low gamma ray background environments to prevent false neutron alarms. The moderate software filter is used in marginally higher gamma ray fields than the liberal filter; however the system does not use the moderate filter in gamma ray fields above $\sim 1 \mathrm{mR} / \mathrm{h}$ to prevent false neutron alarms. The filter used when the system is in the presence of high gamma ray exposure rates $(>1 \mathrm{mR} / \mathrm{h})$ is the conservative software filter. The conservative filter reduces false neutron alarms, but also results in the highest rejection rate for true neutron counts, which significantly decreases the neutron efficiency of the system. Note that for comparison purposes the data were analyzed to provide the results from the three filters for each of the test configurations, however, the user output from the software did not include the results from the three filters under all the tested circumstances (i.e., in the presence of significant gamma ray exposures). The data from each filter were extracted in post analysis.

The data derived from the static tests were the average count rate over the five-minute acquisition time. The background measurements were subtracted from each test configuration to provide the net count rate. The net counts per second obtained with the bare and moderated neutron source for the three software filters and the four moderator thicknesses tested are shown in Figure 6.1. The highest count rate for each filter was obtained with the moderated source and no additional detector moderation. This suggests that even the lowest level of moderation tested $(19 \mathrm{~mm})$ may over-moderate the system. The uncertainty associated with these measurements was based on Poisson statistics and for these tests was less than the size of the plot markers.

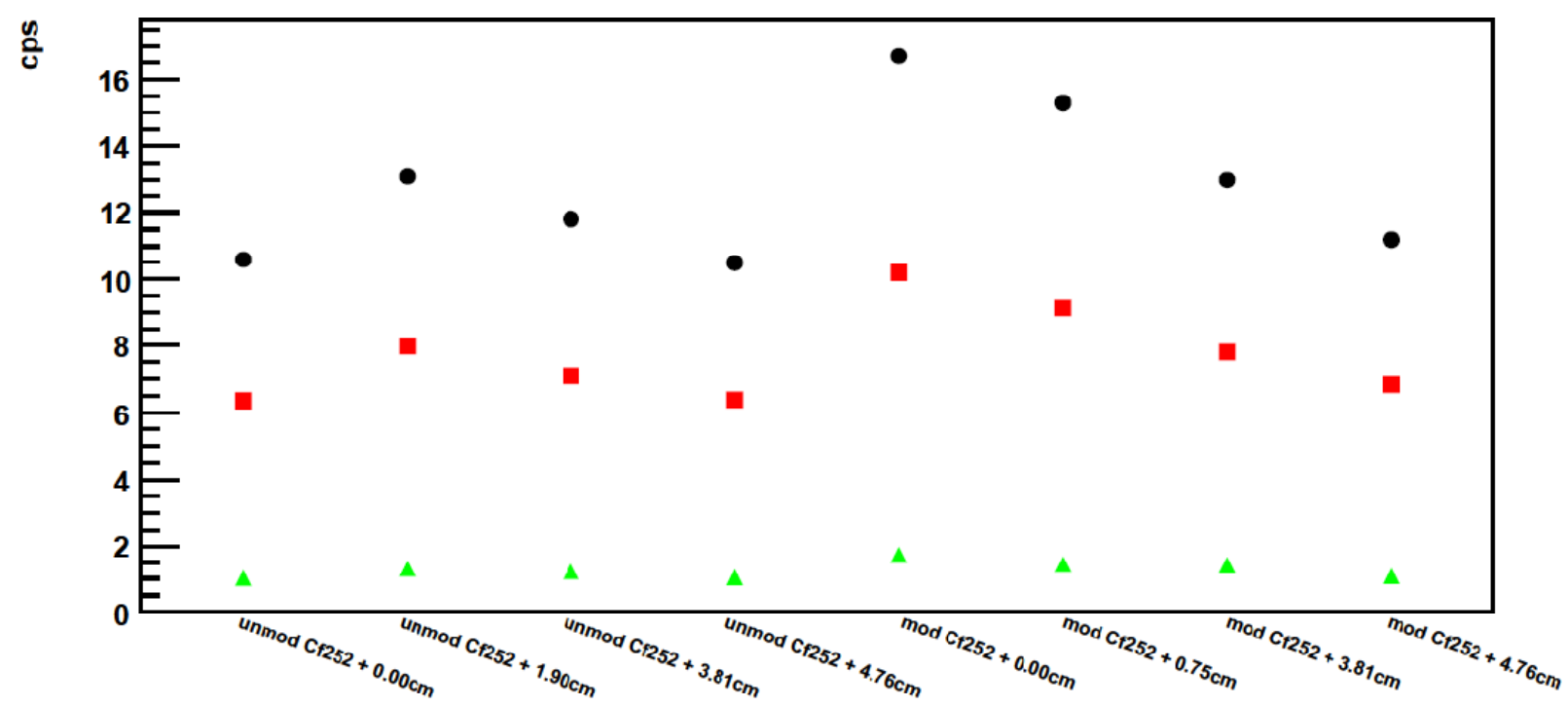

Figure 6.1: Count rate obtained with the three discrimination filters (black=liberal, red=moderate, green=conservative) with the moderated and bare source for four different thicknesses of moderation. 
The net count rate from the static tests was used to determine the neutron detection efficiency of the system. The approximate absolute neutron detection efficiency of the Nucsafe detector was determined by dividing the net count rate obtained with each moderator configuration by the mass (in nanograms) of the ${ }^{252} \mathrm{Cf}$ source, as shown in Figure 6.2 (the highest neutron efficiency attained with each filter is reported in Table 6.7 ). The uncertainty shown in the figure is dominated by the $\sim 15 \%$ source activity uncertainty since statistical uncertainty is very small.

The neutron efficiency that would be obtained with a unit with the same outer moderator box dimensions as the currently deployed moderator box was estimated by scaling the efficiency results by a factor of 5.4. The scaling factor was selected by assuming that the moderation thickness used would be the same regardless of detector size. The total available surface area in the currently deployed system, minus the area required for the moderation, was divided by the surface area of the Nucsafe system (without moderation). The resulting factor was 5.4, which is thus the increase in active area that can likely be accommodated in the SAIC system while still leaving room for electronics. This is a conservative estimate, since scaling of the detector size without the moderator would allow for a factor of $>10$ increase in size. It must be noted that the scaling factor considers only the surface area of the moderator box and does not consider any increase in neutron efficiency that could be achieved from increasing the active volume (i.e., adding more layers of fibers). The potential neutron efficiency of the system scaled by a factor of 5.4 with the moderate filter is $1.72 \pm 0.62 \mathrm{cps} / \mathrm{ng}$, which is below the required value of 2.5 $\mathrm{cps} / \mathrm{ng}$ (though scaling by a factor of 10 would meet the requirement). However, this assumes that the efficiency will increase linearly. Due to these assumptions, scaled efficiencies with the other filters and moderator thicknesses were not considered. Larger detector systems need to be tested to verify any predicted increase in efficiency, which could be substantially more than that estimated here.

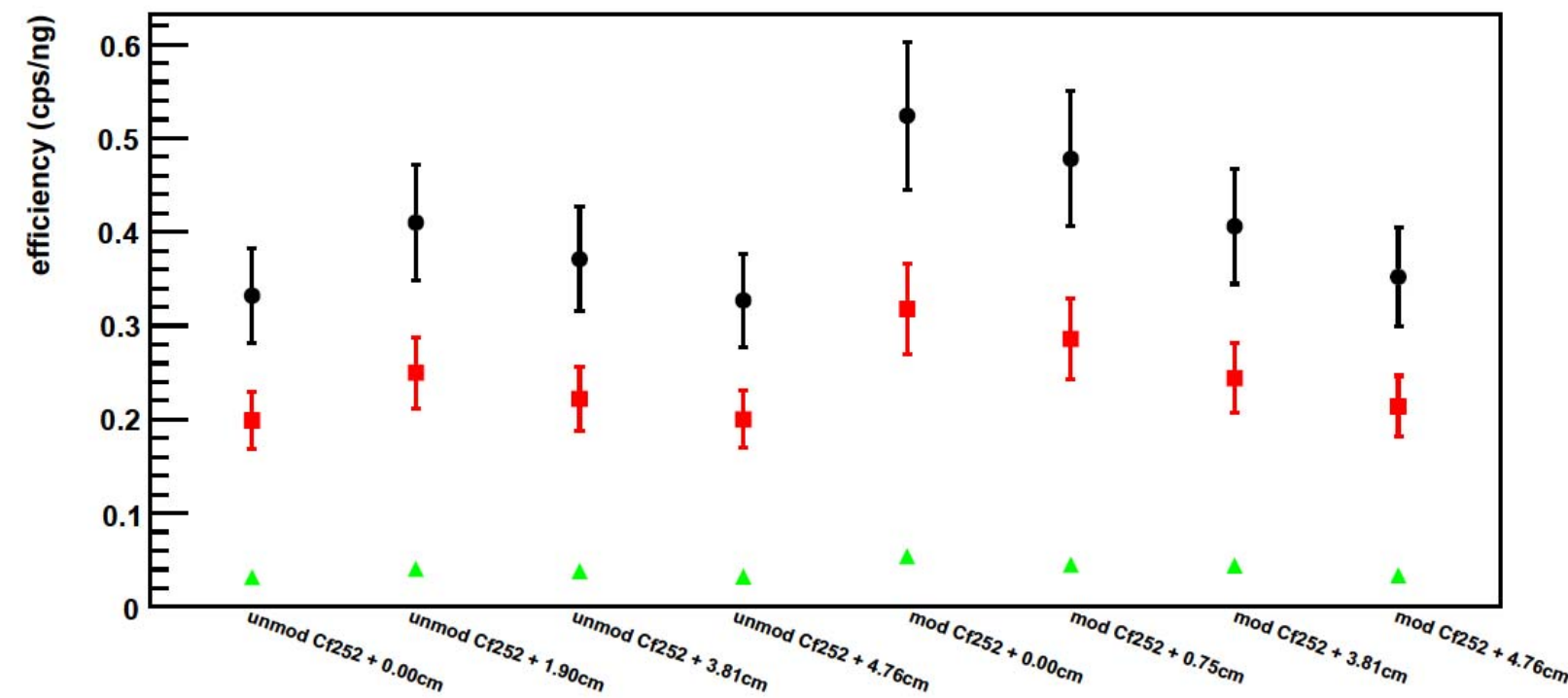

Figure 6.2: Approximate system efficiency calculated for the Nucsafe system tested (black=liberal, red=moderate, green $=$ conservative).

\subsection{Dynamic Test}

The dynamic runs were performed with the source shuttle positioned $2 \mathrm{~m}$ from the ${ }^{3} \mathrm{He}$ system and $1 \mathrm{~m}$ from the Nucsafe detector to increase the signal in the small system. This geometry resulted in approximately four times more counts at the Nucsafe detector than the ${ }^{3} \mathrm{He}$ tubes. However, an increase of 5.4 in the active surface area of the Nucsafe system is the size that can conservatively be accommodated 
in the available space of the currently deployed system (as noted above, this factor might actually be $>10$ ). Thus, the results of the Nucsafe system would need to be scaled by a factor of 1.35 (i.e., 5.4/4) to provide results that would be approximately equal to what would be achieved with a full size system. The difference in the distance between the source and the detector for the dynamic tests performed with the two systems prevents any direct comparison of performance due to the dissimilar solid angles. The closer the system is to the source shuttle the smaller the solid angle will be for that system; thus, while placing the system closer to the shuttle does increase the number of neutrons reaching the system surface it also decreases the amount of time that the system has to "see" the source. Since a direct comparison cannot be made between the ${ }^{3} \mathrm{He}$-based and Nucsafe systems, the results presented compare the count rate obtained dynamically to the count rate obtained statically by the Nucsafe detector. The system that eventually replaces the ${ }^{3} \mathrm{He}$-based system that is currently deployed needs to have similar static and dynamic efficiencies.

The Nucsafe software provides temporal resolution of 0.1 seconds. This high temporal resolution results in spectra that have a large amount of noise, as seen in Figures 6.4 and 6.5. Typical portal monitor applications sum over a longer period of time to increase the signal to noise ratio, so instead of reporting the counts from every tenth of a second, time windows that are wider than the sampling interval have been selected for this analysis. The counts in the window selected were time averaged to produce a 'blurred' count rate for the detector. A window that is wider than the sampling time will improve the statistics, but if the window becomes too wide then the neutron spike that occurred when the source passed in front of the detector will become lost in the background. The results for different windows are shown for the $0.9 \mathrm{~m} / \mathrm{s}(2 \mathrm{mph})$ runs in Table 6.1 and for the $2.2 \mathrm{~m} / \mathrm{s}(5 \mathrm{mph})$ runs in Table 6.2. Dynamic data were acquired for a 5-minute time interval for the $0.9 \mathrm{~m} / \mathrm{s}$ runs, which corresponded to 14 passes of the shuttle. For the $2.2 \mathrm{~m} / \mathrm{s}$ runs, data were acquired for 6 minutes, which corresponded to 34 passes of the shuttle. The count rate from each run for the different time windows were averaged to reduce any individual variability and the uncertainty. The uncertainty for these calculations was based on Poisson statistics and standard error propagation.

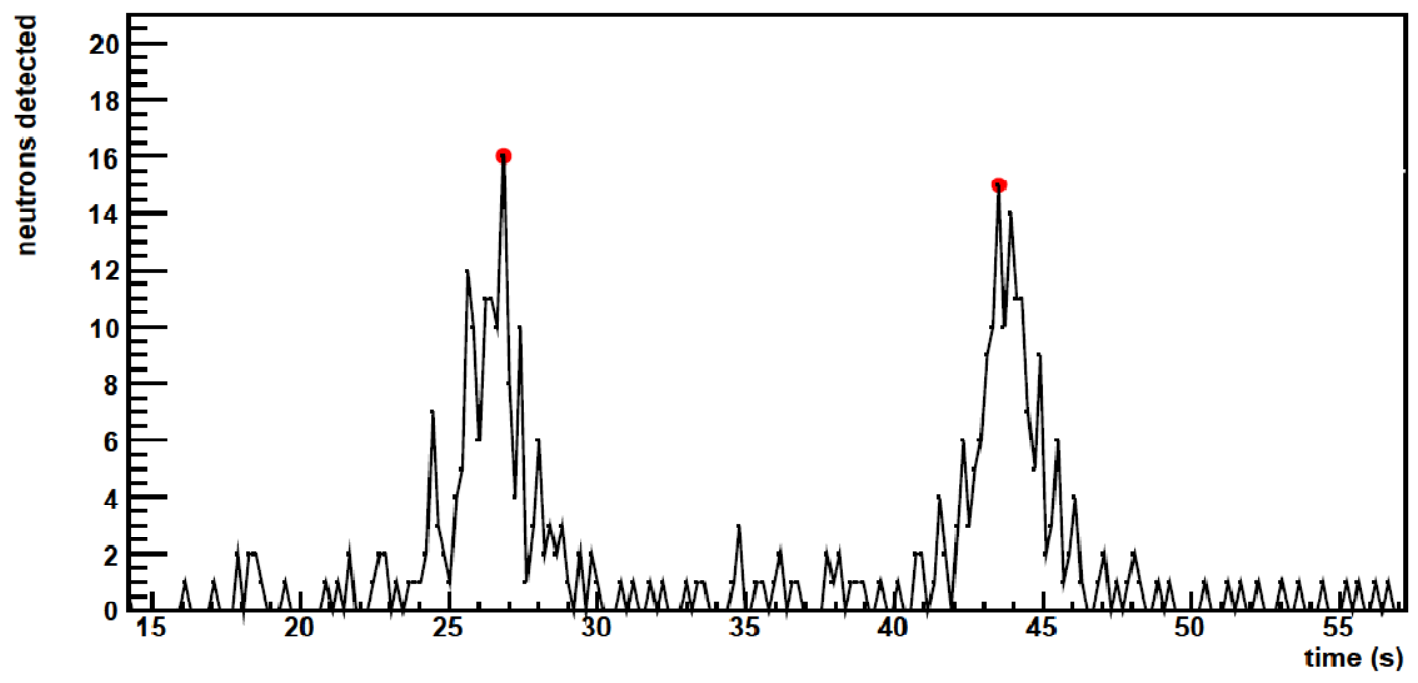

Figure 6.3: Temporal profile for one complete cycle (down and back) of the shuttle at $2 \mathrm{mph}(0.9 \mathrm{~m} / \mathrm{s})$ with the moderated ${ }^{252} \mathrm{Cf}$ source. 


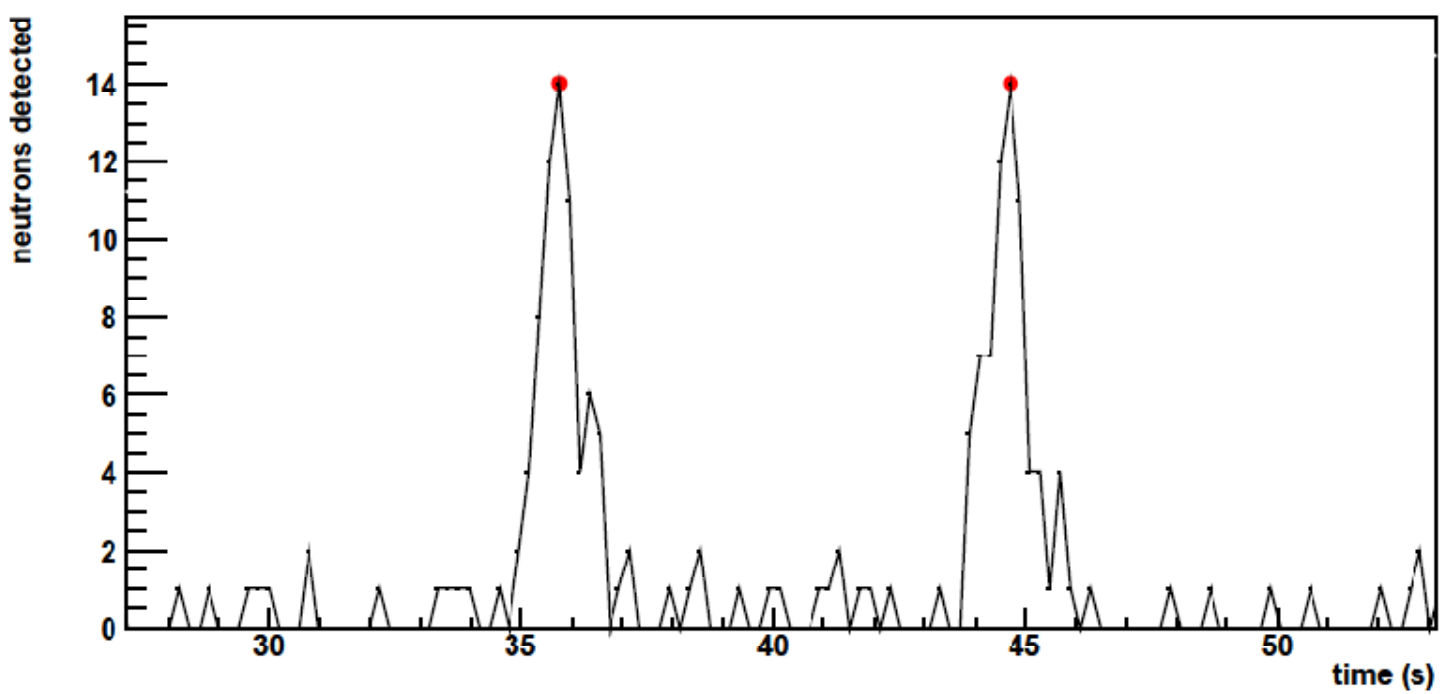

Figure 6.4: Temporal profile for one complete cycle (down and back) of the shuttle at $5 \mathrm{mph}(2.2 \mathrm{~m} / \mathrm{s}) \mathrm{with}$ the moderated source.

Table 6.1: Count rate obtained for different time windows for the $2 \mathrm{mph}(0.9 \mathrm{~m} / \mathrm{s})$ dynamic test.

\begin{tabular}{|c|c|c|}
\hline Window (sec) & cps (average) & Standard Deviation \\
\hline 0.5 & 70.0 & 3 \\
\hline 1 & 55.0 & 2 \\
\hline 2 & 45.0 & 1 \\
\hline 4 & 33.0 & 1 \\
\hline 8 & 19.5 & 0.4 \\
\hline 16 & 10.9 & 0.2 \\
\hline
\end{tabular}

Table 6.2: Count rate obtained for different time windows for the $5 \mathrm{mph}(2.2 \mathrm{~m} / \mathrm{s})$ dynamic test.

\begin{tabular}{|c|c|c|}
\hline Window (sec) & cps (average) & Standard Deviation \\
\hline 0.5 & 57 & 2 \\
\hline 1 & 40 & 1 \\
\hline 2 & 27 & 1 \\
\hline 4 & 15 & 0.3 \\
\hline 8 & 9 & 0.2 \\
\hline 16 & 5 & 0.1 \\
\hline
\end{tabular}

The dynamic results presented for the expanded time windows were acquired with the liberal filter. The static count rate with the liberal filter and the original detector moderation was $15.3 \pm 0.2 \mathrm{cps}$, scaled by a factor of 4 (to account for the difference in distance between the static and dynamic tests) this count rate becomes $61.2 \pm 0.8 \mathrm{cps}$. Therefore the $0.9 \mathrm{~m} / \mathrm{s}(2 \mathrm{mph})$ and $2.2 \mathrm{~m} / \mathrm{s}(5 \mathrm{mph})$ dynamic count rates with a $0.5 \mathrm{sec}$ time window ( 70 and $57 \mathrm{cps}$ respectively) are similar to the static count rate, but a direct comparison is not possible due to the differences in the measurements. These results are approximations as the geometries are not the same for the static and dynamic tests and the scaling factor does not account for all the effects (such as scatter) from the different distances. 


\subsection{Gamma Insensitivity Test}

The detector response to a high gamma ray exposure rate was tested using the ${ }^{60} \mathrm{Co}$ source located in the Building 318. Data were collected over five minute intervals for the four configurations (background, ${ }^{60} \mathrm{Co},{ }^{60} \mathrm{Co}$ with ${ }^{252} \mathrm{Cf}$, and only ${ }^{252} \mathrm{Cf}$ ). The output from the three filters was analyzed for each of the measurement configurations. The difference between the three filters was very pronounced when the system was operated in the presence of gamma rays, as shown in Figure 6.6. The liberal filter resulted in an increase of over $240 \%$ between the neutron count rate recorded with no gamma ray source present and the neutron count rate recorded in the presence of the lowest applied gamma ray exposure rate $(10 \mathrm{mR} / \mathrm{h})$. The neutron count rate recorded with the liberal filter increased up to an exposure rate of $50 \mathrm{mR} / \mathrm{h}$ before beginning to decrease, which indicates that the detector experiences some dead time at count rates higher than $110 \mathrm{cps}$ (Table 6.3). The neutron count rate recorded in the presence of a $10 \mathrm{mR} / \mathrm{h}$ gamma exposure rated with the moderate filter was $30 \%$ higher than the neutron count rate recorded with no gamma source present. The moderate filter rejects significantly more counts than the liberal filter so the detector does not become saturated and thus the count rate increased with increasing gamma exposure rate (Table 6.4). The conservative filter rejects the most gamma ray pulses; the highest increase in neutron count rate recorded with a gamma ray source present compared to without a gamma ray source was $13 \%$ (Table 6.5). However, the conservative filter performs its gamma rejection at the cost of lower neutron sensitivity and, thus, also rejects the most true neutron pulses of the three filters. The intrinsic gamma ray efficiency and GARRn can be derived from these measurements by developing an estimate of the gamma flux at the detector.

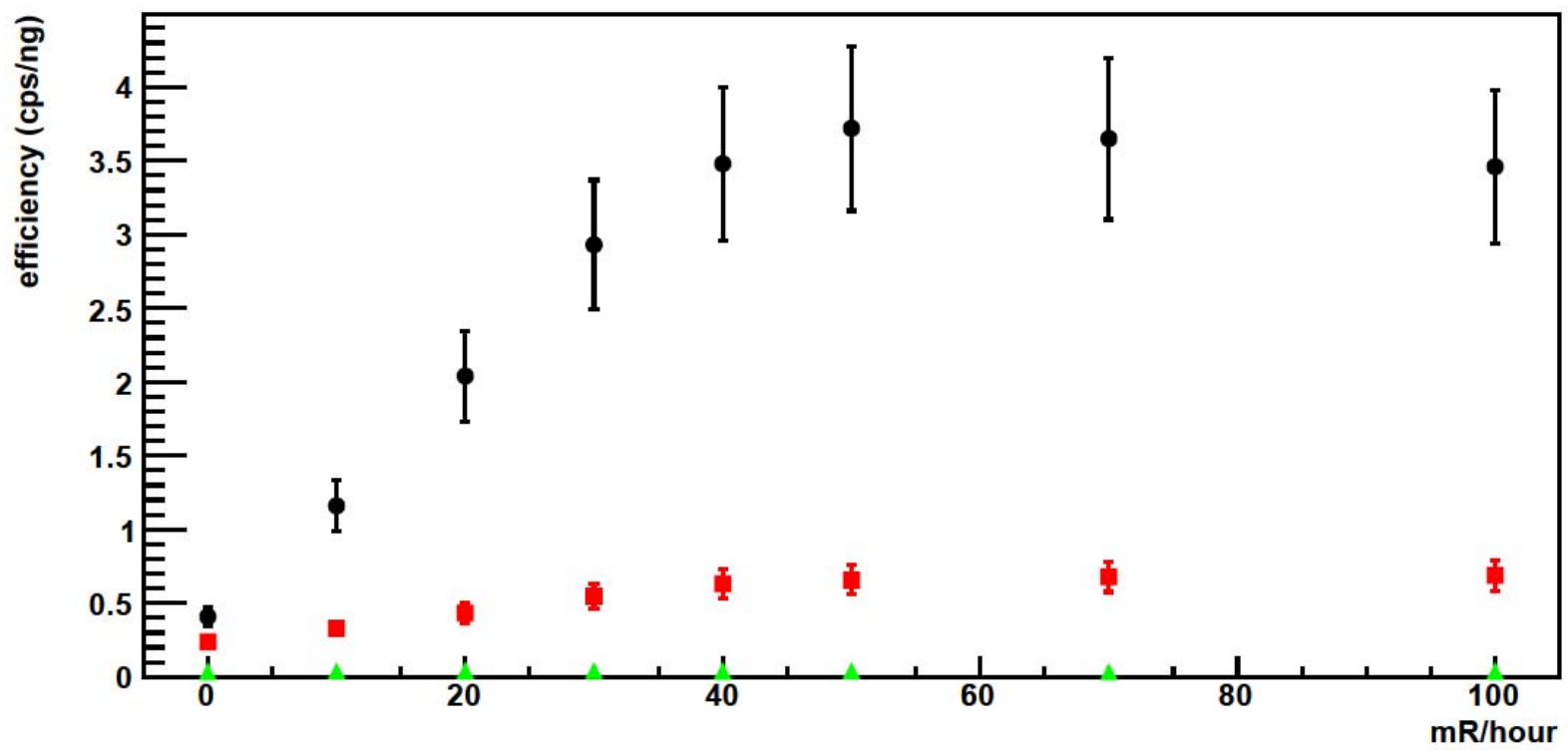

Figure 6.5: Efficiency of the Nucsafe neutron detector in response to a neutron source and a gamma field (black=liberal, red=moderate, green=conservative). 
Table 6.3: Neutron counts recorded with the liberal filter in the presence of a gamma field.

\begin{tabular}{|c|c|c|c|c|}
\hline $\begin{array}{c}\text { Exposure } \\
\text { Rate } \\
(\mathrm{mR} / \mathrm{h})\end{array}$ & $\begin{array}{l}\text { Neutron Counts } \\
\text { with only }{ }^{60} \mathrm{Co} \\
\text { Source (net cps) }\end{array}$ & $\begin{array}{c}17.68 \mu \mathrm{Ci} \\
{ }^{252} \mathrm{Cf} \text { Source } \\
\text { Only (net cps) }\end{array}$ & $\begin{array}{l}\text { Neutron Counts with } \\
{ }^{252} \mathrm{Cf} \text { and }{ }^{60} \mathrm{Co} \\
\text { Sources (net cps) }\end{array}$ & $\begin{array}{c}{\left[\left({ }^{252} \mathrm{Cf} \&{ }^{60} \mathrm{Co} \mathrm{Sources}\right)-\right.} \\
\left.\left({ }^{252} \mathrm{Cf} \text { Source }\right)\right] /{ }^{252} \mathrm{Cf}\end{array}$ \\
\hline 10 & 24 & 14.1 & 36.9 & 1.62 \\
\hline 20 & 52.3 & 14.1 & 65.1 & 3.62 \\
\hline 30 & 83.4 & 14.1 & 93.6 & 5.64 \\
\hline 40 & 104 & 14.1 & 111 & 6.87 \\
\hline 50 & 114 & 14.1 & 119 & 7.44 \\
\hline 70 & 113 & 14.1 & 117 & 7.30 \\
\hline 100 & 108 & 14.1 & 111 & 6.87 \\
\hline
\end{tabular}

Table 6.4: Neutron counts recorded with the moderate filter in the presence of a gamma field.

\begin{tabular}{|c|c|c|c|c|}
\hline $\begin{array}{c}\text { Exposure } \\
\text { Rate } \\
(\mathrm{mR} / \mathrm{h})\end{array}$ & $\begin{array}{l}\text { Neutron Counts } \\
\text { with only }{ }^{60} \mathrm{Co} \\
\text { Source (net cps) }\end{array}$ & $\begin{array}{c}17.68 \mu \mathrm{Ci} \\
{ }_{252} \mathrm{Cf} \text { Source } \\
\text { Only (net cps) }\end{array}$ & $\begin{array}{l}\text { Neutron Counts with } \\
{ }^{252} \mathrm{Cf} \text { and }{ }^{60} \mathrm{Co} \\
\text { Sources (net cps) }\end{array}$ & $\begin{array}{c}{\left[\left(\left(^{252} \mathrm{Cf} \&{ }^{60} \mathrm{Co} \text { Sources }\right)\right.\right.} \\
\left.\left({ }^{252} \mathrm{Cf} \text { Source }\right)\right] / /{ }^{252} \mathrm{Cf}\end{array}$ \\
\hline 10 & 3.06 & 8.09 & 10.5 & 0.30 \\
\hline 20 & 7.15 & 8.09 & 13.8 & 0.71 \\
\hline 30 & 12 & 8.09 & 17.5 & 1.16 \\
\hline 40 & 15 & 8.09 & 20.2 & 1.50 \\
\hline 50 & 17.6 & 8.09 & 21 & 1.60 \\
\hline 70 & 19.3 & 8.09 & 21.7 & 1.68 \\
\hline 100 & 19.7 & 8.09 & 22 & 1.72 \\
\hline
\end{tabular}

Table 6.5: Neutron counts recorded with the conservative filter in the presence of a gamma field.

\begin{tabular}{|c|c|c|c|c|}
\hline $\begin{array}{c}\text { Exposure } \\
\text { Rate } \\
(\mathrm{mR} / \mathrm{h})\end{array}$ & $\begin{array}{l}\text { Neutron Counts } \\
\text { with only }{ }^{60} \mathrm{Co} \\
\text { Source (net cps) }\end{array}$ & $\begin{array}{c}17.68 \mu \mathrm{Ci} \\
{ }^{252} \mathrm{Cf} \text { Source } \\
\text { Only (net cps) }\end{array}$ & $\begin{array}{l}\text { Neutron Counts with } \\
{ }^{252} \mathrm{Cf} \text { and }{ }^{60} \mathrm{Co} \\
\text { Sources (net cps) }\end{array}$ & $\begin{array}{c}{\left[\left({ }^{252} \mathrm{Cf} \mathrm{\&}{ }^{60} \mathrm{Co} \mathrm{Sources}\right)\right.} \\
\left.\left.\left({ }^{252} \mathrm{Cf} \text { Source }\right)\right] /\right]^{252} \mathrm{Cf}\end{array}$ \\
\hline 10 & 0.158 & 1.27 & 1.35 & 0.06 \\
\hline 20 & 0.302 & 1.27 & 1.35 & 0.06 \\
\hline 30 & 0.511 & 1.27 & 1.44 & 0.13 \\
\hline 40 & 0.653 & 1.27 & 1.28 & 0.01 \\
\hline 50 & 0.754 & 1.27 & 1.37 & 0.08 \\
\hline 70 & 0.789 & 1.27 & 1.16 & -0.09 \\
\hline 100 & 0.85 & 1.27 & 1.27 & 0 \\
\hline
\end{tabular}

\section{${ }^{60}$ Co Gamma Flux Estimate}

The exact strength of the ${ }^{60} \mathrm{Co}$ source used for these measurements was unknown and, as the measurements were made indoors, scatter was assumed to be a contributing factor to the exposure rate at the detector. Thus, the gamma flux at the detector was estimated from the effective activity, which was calculated with the measured exposure rate at the detector and the gamma factor for ${ }^{60} \mathrm{Co}(13.2$ $\mathrm{R} \cdot \mathrm{cm}^{2} / \mathrm{h} \cdot \mathrm{mCi}$ ). The effective activity is defined as the source activity that would be required to produce the measured exposure rate at the distance from the source to the detector. The effective activity was used to calculate the flux on the surface area of the moderating box $\left(0.13 \mathrm{~m}^{2}\right)$. The results are shown in Table 6.6. 
Table 6.6: Estimated number of photons incident on the active area of the detector calculated using the effective activity for each of the exposure rates.

\begin{tabular}{|c|c|c|c|}
\hline $\begin{array}{c}\text { Exposure Rate } \\
(\mathbf{m R} / \mathbf{h})\end{array}$ & $\begin{array}{c}\text { Detector to } \\
\text { Source Distance } \\
(\mathbf{m})\end{array}$ & $\begin{array}{c}\text { 'Effective' Source } \\
\text { Activity (Ci) }\end{array}$ & $\begin{array}{c}\text { Estimated } \\
\text { Photons on } \\
\text { Detector From } \\
\text { Effective Activity } \\
\text { (cps) }\end{array}$ \\
\hline 10 & 3.88 & 0.114 & $5.91 \mathrm{E}+06$ \\
\hline 20 & 2.74 & 0.114 & $1.19 \mathrm{E}+07$ \\
\hline 30 & 2.24 & 0.114 & $1.77 \mathrm{E}+07$ \\
\hline 40 & 1.94 & 0.114 & $2.37 \mathrm{E}+07$ \\
\hline 50 & 1.73 & 0.136 & $2.97 \mathrm{E}+07$ \\
\hline 70 & 1.47 & 0.131 & $4.12 \mathrm{E}+07$ \\
\hline 100 & 1.23 & 0.115 & $5.88 \mathrm{E}+07$ \\
\hline
\end{tabular}

A value for efficiency and GARRn (Kouzes et al., 2009) can be estimated from the calculated photon flux on the detector and the absolute neutron efficiency. The absolute neutron detection efficiency value used for the determination of GARRn was the value associated with the geometry for each of the detector locations. The neutron source was located on the backside of the detector for the gamma measurements so the neutron efficiency used to calculate GARRn was calculated with the neutron source $2 \mathrm{~m}$ from the back of the detector. Thus, the effect of geometry on the value of GARRn cancelled in the calculation as the geometry was the same for $\epsilon_{\mathrm{abs} \gamma \mathrm{n}}$ and $\epsilon_{\mathrm{abs} \mathrm{n}}$. The highest absolute neutron efficiencies achieved with each of the filters (obtained with no moderation on the front of the detector) and the absolute neutron efficiencies used to calculate GARRn are reported in Table 6.7. The GARRn values for the liberal and moderate filters are outside of the specified window $(0.9 \leq$ GARRn $\leq 1.10)$ for all of the applied gamma ray exposure rates. For the conservative filter, the GARRn value is within the specified range for all of the gamma ray exposure rates, but this comes at the expense of extremely low absolute neutron efficiency (best case is 0.05 , un-scaled). Testing of a full size unit is required to verify these values for a larger system.

The detector system tested had intrinsic gamma ray efficiencies $\left(\epsilon_{\text {int }} \gamma \mathrm{n}\right)$ on the order of $10^{-6}$ with the liberal and moderate filters for all of the exposure rates tested. The intrinsic gamma ray efficiency with the conservative filter was on the order of $10^{-8}$ for all of the exposure rates. The required intrinsic gamma ray efficiency is $10^{-6}$, so for a detector of the size tested all three filters would meet this requirement.

However, the intrinsic gamma ray efficiencies for a given detection technology are dependent on the detector size, and therefore would potentially be different for a detector size (larger) that would meet the absolute efficiency requirements. Although promising, the intrinsic gamma ray efficiency would need to be quantified for a larger detector.

6.7: Estimates for the Absolute Efficiency and the Intrinsic Gamma Ray Efficiency and GARRn at a gamma exposure rate of $10 \mathrm{mR} / \mathrm{h}$.

\begin{tabular}{|c|c|c|c|c|}
\hline Filter & $\begin{array}{c}\text { Absolute Efficiency } \\
\text { (best case) } \\
\mathbf{\epsilon}_{\text {abs n }}\end{array}$ & $\begin{array}{c}\text { Absolute Efficiency } \\
\text { for GARRn }\end{array}$ & $\begin{array}{c}\text { Intrinsic Gamma } \\
\text { Ray Efficiency } \\
\mathbf{\epsilon}_{\text {int } \boldsymbol{~} \mathbf{n}}\end{array}$ & $\begin{array}{c}\text { GARRn } \\
\mathbf{\epsilon}_{\text {abs } \gamma \mathbf{n}} / \mathbf{\epsilon}_{\text {abs n }}\end{array}$ \\
\hline Conservative & 0.05 & 0.01 & $1.49 \mathrm{E}-8$ & $1.07(6)$ \\
\hline Moderate & 0.32 & 0.04 & $4.63 \mathrm{E}-7$ & $1.31(3)$ \\
\hline Liberal & 0.52 & 0.07 & $3.94 \mathrm{E}-6$ & $2.70(4)$ \\
\hline
\end{tabular}




\section{Conclusions}

The Nucsafe neutron detection system has been tested as a possible alternative neutron detection technology. The Nucsafe detector uses lithium loaded glass fibers to detect neutrons. Gamma ray discrimination is performed by three different filters, depending on the strength of the gamma field, with varying levels of gamma ray pulse rejection. The tests were conducted on a Nucsafe detector with an active area of $0.04125 \mathrm{~m}^{2}$.

The absolute neutron efficiencies obtained with this system for the three software filters and the original detector moderation were as follows. For the liberal filter the absolute neutron detection efficiency was $0.478 \pm 0.072 \mathrm{cps} / \mathrm{ng}$, for the moderate filter $0.286 \pm 0.043 \mathrm{cps} / \mathrm{ng}$, and $0.045 \pm 0.007 \mathrm{cps} / \mathrm{ng}$ for the conservative filter. A larger system would have to be tested to determine if the efficiency scales linearly with detector size and if additional efficiency can be gained by increasing the number of layers of fibers. Larger Nucsafe systems also need to be tested to determine if there is a significant loss of efficiency in scale-up from such effects as the signal travelling a longer distance in the fibers and increased pulse rejection.

Test results indicate that adequate gamma rejection is obtained with all three filters at all of the exposure rates tested, but with a significant loss in neutron detection efficiency. However, this would need to be verified with a larger system as the results with the liberal filter was extremely close to the required value. For the conservative filter the gamma rejection factor is estimated to be on the order of $10^{-8}$ for all of the tested exposure rates (up to $100 \mathrm{mR} / \mathrm{h}$ from a ${ }^{60} \mathrm{Co}$ source).

The GARRn value is outside of the desired range even at the lowest exposure rate tested $(10 \mathrm{mR} / \mathrm{h})$ for both the liberal and moderate filters, indicating that there is miscounting of neutrons in the presence gamma ray exposure. The GARRn value with the conservative filter is within the desired range for all of the exposure rates tested, however, the neutron efficiency is very low with this filter and does not meet the requirement.

Thus, the Nucsafe system tested could not simultaneously meet all three detection criteria with a single software filter. A larger system needs to be tested to verify that the efficiency scales linearly and to determine if the susceptibility to gamma radiation falls within the required range. Optimization of the design might allow a more conservative analysis with better gamma ray rejection while retaining the required neutron efficiency. 


\section{References}

ANSI. 2004. American National Standard for Evaluation and Performance of Radiation Detection Portal Monitors for Use in Homeland Security. Technical Report. ANSI 42.35, American Nuclear Standards Institute, Washington, D.C.

Knoll GF. 2002. Radiation Detection and Measurement $3^{\text {rd }}$ Ed. John Wiley and Sons, New York.

Kouzes RT, J Ely, and E Siciliano. 2007. Neutron Alarm Algorithms for Deployed RPMs. PIET-43741TM-663, PNNL-17101, Pacific Northwest National Laboratory, Richland, Washington.

Kouzes, RT, JH Ely, PE Keller, RJ McConn, and ER Siciliano. 2008. "Passive Neutron Detection for Interdiction of Nuclear Material at Borders." Nuclear Instruments and Methods in Physics Research Section A: Accelerators, Spectrometers, Detectors and Associated Equipment 584(2-3): 383-400.

Kouzes, RT. 2009. “The ${ }^{3}$ He Supply Problem," Pacific Northwest National Laboratory Report PNNL18388.

Kouzes RT, Ely J, Lintereur A, Stephens D. 2009. Neutron Detector Gamma Insensitivity Criteria. PNNL-18903, Pacific Northwest National Laboratory, Richland, Washington.

Stromswold D, J Ely, R Kouzes, J Schweppe. 2003. Specifications for Radiation Portal Monitor Systems Revision 6.7. PIET-43741-TM-017, Pacific Northwest National Laboratory, Richland, Washington.

Van Ginhoven, RM, RT Kouzes, DL Stephens, 2009. “Alternative Neutron Detector Technologies for Homeland Security,” Pacific Northwest National Laboratory Report PNNL-18471. 


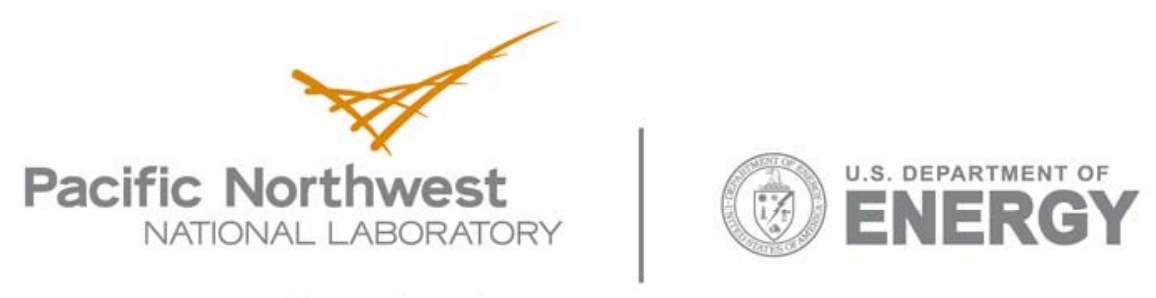

902 Battelle Boulevard

P.O. Box 999

Richland, WA 99352

1-888-375-PNNL (7665)

www.pnl.gov 